\title{
Predictors of Preventive Practices on Hypertension Among Adults in Ikoyi Nigeria
}

\author{
Tajudeen Olusegun Rasheed ${ }^{1,}$, , Abdulkareem Durosinlorun ${ }^{2}$ \\ ${ }^{1}$ Medical Department, Economic and Financial Crimes Commission, Ikoyi, Nigeria \\ ${ }^{2}$ Veterenary Services and Pest Control Department, Federal Ministry of Agriculture and Rural Development, Kaduna, Nigeria
}

Email address:

rashtaj2005@yahoo.com (T. O. Rasheed)

${ }^{*}$ Corresponding author

\section{To cite this article:}

Tajudeen Olusegun Rasheed, Abdulkareem Durosinlorun. Predictors of Preventive Practices on Hypertension Among Adults in Ikoyi Nigeria. European Journal of Preventive Medicine. Vol. 6, No. 5, 2018, pp. 64-69. doi: 10.11648/j.ejpm.20180605.11

Received: September 8, 2018; Accepted: October 15, 2018; Published: November 9, 2018

\begin{abstract}
Background: hypertension is one of the leading causes of disability and death worldwide. But despite this fact, adult's rarely gives deserved attention to preventive practices on hypertension. Objective: to examine the predictors of preventive practices on hypertension among adults in Ikoyi, Nigeria. Method: the survey was a descriptive and cross-sectional design, a random sampling technique was used to select $\mathrm{N}=149$ adults from a cluster of the participants. A self-administered questionnaire with validity and reliability established was used to collect data on predictors that influence compliance with preventive practices on hypertension. Chi-square statistical model was used to test the stated hypotheses at $\mathrm{p}<0.05$. Results: the finding indicated that participants seldom checked their blood pressure unless on consultation in the health institutions. Variables' such as age, gender, marital status, education attainment, knowledge of the risk factors and knowledge of complications of hypertension, were all predictors of preventive practices on hypertension except occupational status that was not significant at $\mathrm{X}^{2}=11.6, \mathrm{df}=4, \mathrm{p}=0.060$ in this study. Conclusion: adult should not wait to attain definite age bracket or belong to a status before engaging in active preventive practices on hypertension considering the associated peril and complications of the disease.
\end{abstract}

Keywords: Hypertension, Predictors, Preventive Practices, Nigeria

\section{Introduction}

Hypertension is one of the most common worldwide diseases afflicting humans with serious consequences and it could be detected in adults by indication of high blood pressure measurement [1]. Adults could adopt preventive practices on hypertension through lifestyle modification by complying with healthy dietary regimen, reducing salt in diet, maintaining healthy weight, watch waistline, exercise regularly, limiting alcohol drink, quitting smoking, cutting down on caffeine intake, reducing stress, monitoring blood pressure, seeking support and having adequate rest and sleep [2].

Hypertension occurs if an individual has a blood pressure of $\geq 140 / 90 \mathrm{mmHg}$ based on three or more readings on separate occasions [3]. Hypertension is a latent disorder as it has a long asymptomatic phase and this characteristic gives the disease the name "silent killer" [4]. Over 7 million deaths globally were attributed to hypertension in 2016 and the burden was approximately shared equally by both genders [5]. More of the Daily Adjustment Life Years (DALY) burden was experienced in developing countries compared to developed countries, reflecting the high risk-factor in developing countries [6].

Nigeria with a population of more than 170 million people had crude prevalence of hypertension to be between $38.8 \%$ $44.5 \%$ (based on blood pressure threshold of 140/90 $\mathrm{mmHg}$ ) and an age-adjustment ratio of $9.3 \%$ [7]. This number translates into more than 20.8 million Nigerians aged 20 years and above hypertensive [7]. However, according to the current definition of hypertension from the Eighth Joint National Committee on Prevention, Detection, Evaluation and treatment of High Blood pressure (JNC 8) guidelines, many more Nigerians $(38.8 \% 44.5 \%)$ could be classified as hypertensive [7]. 
In a study conducted by the International Collaborative Study of Hypertension in Blacks (ICSHIB), the age-adjusted prevalence of hypertension in Nigeria was $(29.5 \%$ for men and $25.0 \%$ for women) [7-8]. Hypertension and its complications constitute $25 \%$ of emergency medical admission in Nigeria hospitals [9-11]. The complications include left ventricular hypertrophy, diastolic dysfunction, congestive heart failure; ischemic heart disease, stroke, and renal failure are well documented by researchers [12]. The autopsy reports from a teaching hospital in Nigeria found that the most common cause of sudden death was the complications of hypertension in most medical emergency cases and for this reason, there is need for positive behavioral change on preventive practices [13].

The Bandura's theory of social learning was applied to this study and it explains human behavior in terms of reciprocal interaction between cognitive, behavioral and environmental influences [14]. The theory encompasses attention, memory and motivation and its application focuses on positive behavioral change, using both internal and external milieu of individual [14]. The theory demonstrated that adults could be able to achieve preventive practices on hypertension if knowledge of why, when, and how to carry out preventive practices as expected is explained to them. Furthermore, adults having information of the benefits or otherwise could serve as a motivating factor towards achieving positive social change [14].

Conclusively, the level of the aspiration and awareness that an adult has on hypertension could influence preventive practices adherence level. In order to improve adult's skill and level of performance, the use of reinforcement of the awareness campaign on hypertension could sustain the positive social changes towards healthy living. This study examined the predictors of preventive practices on hypertension among adults in Ikoyi, Nigeria at various levels of individual in the community. The justification for this study is that hypertension affects various levels of people in the society from age 20 years and above, which are the productive age group [15]. Also, hypertension could be prevented through effective healthy lifestyle modification as emphasized by researchers [16]. Furthermore, considering the information on the burden of the disease, this study intends to emphasize and reinforce the strategies towards prevention and control of hypertension and the main objective of this study is to ascertain the combination of the predictors that could positively influence preventive practices on hypertension.

\section{Method}

\subsection{Study Setting}

This study was conducted in Ikoyi, one of the communities in the Eti-Osa local government area of Lagos State, Nigeria. Ikoyi is an Island that lies at the edge of the Lagoon. It was originally part of Lagos Island until it was separated by a narrow waterway that was dug by the British colonial.
Buildings have now been erected on the canal or filled with sand; so, the two Islands have been fused together again. Ikoyi is shielded from the Atlantic Ocean by Victoria Island and the broad sand spit runs east down the coastline. There are banks, fast food outlets, filling stations, shopping malls, religious centres, schools, office complex and residential houses.

\subsection{Research Design}

This study was a cross-sectional survey design and random sampling technique was used to select the $\mathrm{N}=149$ participants. Chi-square statistical model was used to test the association that exists between dependent and independent variables. The study assessed the independent variables that were predictors of prevention on hypertension.

\subsection{Target Population}

The target population for the study included adults (age 20 years and above, males and females, living and working in various parts of the Ikoyi community. The total number of participants surveyed in this study was one hundred and forty-nine $\mathrm{N}=149$.

\subsection{Sample Size Determination}

The minimum sample size was determined, using the prevalence of hypertension in Nigeria and it was calculated using the formula thus:

$$
\mathrm{N}=\frac{\mathrm{z}^{2} \mathrm{pq}}{\mathrm{e} 2 a}
$$

$\mathrm{N}$-minimum sample size for a statistically significant survey.

z -standard normal deviation at 95\% confidence limit $=1.96$

p- prevalence of hypertension in Nigeria using ageadjusted ratio is $11.2 \%$ [10]

$$
q(1-p)
$$

e Margin of error acceptable or measure of precision usually set at 0.05 .

$$
N=\frac{\{1.96\}^{2}\{0.11\}(0.89)}{\{0.05\}^{2}}
$$

$\mathrm{N}=149$ (minimum sample size).

\subsection{Sampling Procedure}

The sampling technique used was a random sampling method. Participants were selected from the cluster of adults in the Ikoyi community. The population surveyed was divided into 3 geographical zones, then organizational zones, and individual levels. At every stage, a proportion of the corresponding stratum was selected. The studied participants were chosen from each stratum at individual level by a random systematic sampling technique of 1 in 5 . This process 
continued until $\mathrm{N}=149$ participants were selected.

\subsection{Instrument for Data Collection}

The instrument used for data collection was a questionnaire that was divided into 3 sections. The first section contained demographic variables, while the second and third sections contained the predictors, practices of blood pressure check, risk factors and complications of hypertension. The measurement of the rating of the participants was expressed, using "YES", "NO" and "NOT SURE". The questionnaire used for this study was tested for validity and reliability. The face, empirical, constructs and content validity of the questionnaire were established and found to be appropriate. Descriptive statistics was done using absolute numbers and percentages. The Chi-square statistical test was used to test the association that exists between the categorical variables at $p<0.05$ and $95 \%$ confidence interval.

\subsection{Data Collection and Analysis}

The data were collected during the day in Ikoyi. The questionnaires were administered to the participants daily for a period of 2 months until the required data were collected. At every stage, a proportion of the corresponding stratum was selected. The studied participants were chosen from each stratum at individual level by a random systematic sampling. The data collected were then collated, analyzed and processed electronically, using SPSS version 21.0 statistical software.

\subsection{Measurement of Variables}

In this study, the dependent variable (outcome variable) is the preventive practices on hypertension as well as the primary variable. The blood pressure check is the secondary outcome variable. The independent variables were: knowledge of risk factors of hypertension, knowledge of complications of hypertension, age, gender, marital status, occupational status and education attainment. There were 40 questions in all. A method of scoring and categorization system on the level of preventive practices was adopted in which participants who scored $<20$ points $(<50 \%)$ out of the questions on preventive practices were rated poor (inadequate), those who scored $20-27$ points (50-69\%) were rated satisfactory (fair) while participants who scored 28 points and above $(\geq 70 \%)$ were rated good (adequate). There were 7 questions on the practice of blood pressure check and this was used to categorize the practice as follows: Good practices $=$ when an adult carried out blood pressure check regularly from one to three times monthly. Poor practices $=$ when an adults carried out blood pressure check within 6 months to 1 year, or only on consultation and never checked.

\subsection{Ethical Consideration}

Permission to conduct this study was obtained from the ethic and research committee of the Lagos State University College of Medicine, Lagos, Nigeria. Participants were informed of the study verbally and they consented by filling the consent form, which clearly explained the purpose of the study as well as the benefits to the participants. They were requested not to put any identifier on the survey forms to ensure anonymity of the data. The procedures, during the conduct of this study, followed the standard stipulated in the studies involving human participants. Participation was out of free consent. Participants were informed that they had the right to withdraw from the study at any time without any adverse consequence.

\section{Results}

\subsection{Demographic Characteristics and Preventive Practices on Hypertension}

A total of $\mathrm{N}=149$ (96.12\%) were successfully surveyed. Table 1 shows that majority of the participants $(91.3 \%)$ were aged between 20-59 years, with mean age of $38.7 \pm 9.2$ years. One third of the participants $n=95(63.8 \%)$ were males while $\mathrm{n}=54(36.2 \%)$ were females. More than half of the participants, $\mathrm{n}=79(53.0 \%)$ had post secondary school education and $16(10.7 \%)$ had no formal education. Also, Table 1 shows that association exists between demographic characteristics and preventive practices on hypertension among the participants. Fifty eight participants $n=58,39 \%$ were found to observe preventive practices on hypertension. Age, marital status, sex and educational attainment were predictors of preventive practices on hypertension based on the significant level of $\mathrm{p}<0.005$ at $95 \%$ confidence interval. Contrarily, there was no significant association between occupational status of the participants and preventive practices on hypertension.

Table 1. Association between participants' demographic characteristics and preventive practices on hypertension Lagos, Nigeria, May 2017.

\begin{tabular}{|c|c|c|c|c|c|}
\hline \multirow{2}{*}{ Variable } & \multicolumn{4}{|c|}{ Hypertension Prevention Prediction level N=149(\%) } & \multirow{2}{*}{$\begin{array}{l}\text { Statistical analysis } \\
\text { p-value }\end{array}$} \\
\hline & Inadequate 73 & Fair 18 & Adequate 58 & Total (\%) & \\
\hline \multicolumn{6}{|l|}{ Age (Years) } \\
\hline $20-29$ & $27(93.2)$ & $1(3.4)$ & $1(3.4)$ & 29 & \\
\hline $30-39$ & $15(33.3)$ & $4(8.9)$ & $26(57.8)$ & 45 & $\mathrm{X}^{2}=38.5$ \\
\hline $40-49$ & $13(35.1)$ & $7(18.9)$ & $17(46.0)$ & 37 & $\mathrm{df}=4$ \\
\hline $50-59$ & $15(60.0)$ & $4(16.0)$ & $6(24.0)$ & 25 & $\mathrm{p}=0.001$ \\
\hline$\geq 60$ & $3(23.1)$ & $2(15.4)$ & $8(61.5)$ & 13 & \\
\hline Total & 73 & 18 & 58 & $149(100)$ & \\
\hline \multicolumn{6}{|l|}{ Occupational status } \\
\hline Unemployed & $5(50.0)$ & $2(20.0)$ & $3(30.0)$ & 10 & \\
\hline Unskilled & $21(68.0)$ & $2(6.4)$ & $8(25.6)$ & 31 & $X^{2}=11.6$ \\
\hline
\end{tabular}




\begin{tabular}{|c|c|c|c|c|c|}
\hline \multirow{2}{*}{ Variable } & \multicolumn{4}{|c|}{ Hypertension Prevention Prediction level N=149(\%) } & \multirow{2}{*}{$\begin{array}{l}\text { Statistical analysis } \\
\text { p-value }\end{array}$} \\
\hline & Inadequate 73 & Fair 18 & Adequate 58 & Total (\%) & \\
\hline Semi-skilled & $17(43.6)$ & $5(12.8)$ & $17(43.6)$ & 39 & $\mathrm{df}=4$ \\
\hline Professional & $25(40.3)$ & $8(12.9)$ & $29(46.8)$ & 62 & $\mathrm{p}=0.060$ \\
\hline Students & $5(71.4)$ & $1(14.3)$ & $1(14.3)$ & 07 & \\
\hline Total & 73 & 18 & 58 & $149(100)$ & \\
\hline \multicolumn{6}{|l|}{ Marital status } \\
\hline Single & $45(81.8)$ & $8(14.6)$ & $2(3.6)$ & 55 & $X^{2}=49.7$ \\
\hline Married & $23(29.1)$ & $7(8.9)$ & $49(62.0)$ & 79 & $\mathrm{df}=2$ \\
\hline Others & $5(33.3)$ & $3(20.0)$ & $7(46.7)$ & 15 & $\mathrm{p}=0.001$ \\
\hline Total & 73 & 18 & 58 & $149(100)$ & \\
\hline \multicolumn{6}{|l|}{ Sex } \\
\hline Male & $53(64.6)$ & $6(7.4)$ & $23(28.0)$ & 82 & $\mathrm{X}^{2}=18.0, \mathrm{df}=1$ \\
\hline Female & $20(29.9)$ & $12(17.9)$ & $35(52.2)$ & 67 & $\mathrm{p}=0.010$ \\
\hline Total & 73 & 18 & 58 & $149(100)$ & \\
\hline \multicolumn{6}{|l|}{ Education level } \\
\hline No formal education & $14(87.5)$ & $2(12.5)$ & $0(00.0)$ & 16 & \\
\hline Primary & $10(52.6)$ & $5(26.3)$ & $4(21.1)$ & 19 & $X^{2}=27.5$ \\
\hline Secondary & $14(40.0)$ & $6(17.1)$ & $15(42.9)$ & 35 & $\mathrm{df}=3$ \\
\hline Post secondary & $35(44.3)$ & $5(6.3)$ & $39(49.4)$ & 79 & $\mathrm{p}=0.001$ \\
\hline Total & 73 & 18 & 58 & $149(100)$ & \\
\hline
\end{tabular}

\subsection{Knowledge and Preventive Practices on Hypertension}

In Table 2, the variable such as knowledge of risk factors of hypertension, knowledge that hypertension is symptomless and is controllable, were all significantly associated with preventive practices on hypertension at $p<0.05$. The knowledge of stroke as a complication of hypertension was not significantly associated with preventive practices on hypertension.

Table 2. Association between participants' knowledge and preventive practices on hypertension Lagos, Nigeria, May 2017

\begin{tabular}{|c|c|c|c|c|}
\hline \multirow[t]{2}{*}{ Variable } & \multicolumn{2}{|c|}{ Hypertension Prevention Prediction Level } & \multirow[t]{2}{*}{ Total N=149 } & \multirow[t]{2}{*}{ Statistical analysis p-value } \\
\hline & YES (Freq.\%) & NO (Freq.\%) & & \\
\hline \multirow{3}{*}{ Knowledge of the risk factors of hypertension } & Yes 43(53.8) & $37(46.2)$ & 80 & $X^{2}=13.05$ \\
\hline & No $17(24.6)$ & $52(75.4)$ & 69 & $\mathrm{df}=1, \mathrm{p}=0.000$ \\
\hline & 60 & 89 & $149(100)$ & \\
\hline \multirow{3}{*}{ Knowledge that hypertension is symptomless } & Yes $15(37.5)$ & $38(62.5)$ & 53 & $\mathrm{X}^{2}=11.9$ \\
\hline & No 41(30.4) & $55(69.6)$ & 96 & $\mathrm{df}=1, \mathrm{p}=0.001$ \\
\hline & 56 & 93 & $149(100)$ & \\
\hline \multirow{2}{*}{$\begin{array}{l}\text { Knowledge of stroke as a complication of } \\
\text { hypertension }\end{array}$} & No 21(59.3) & $6(40.7)$ & 27 & $\mathrm{df}=1, \mathrm{p}=0.536$ \\
\hline & 141 & 8 & $149(100)$ & \\
\hline \multirow{3}{*}{$\begin{array}{l}\text { Knowledge that hypertension can only be } \\
\text { controlled }\end{array}$} & Yes $15(37.5)$ & $5(4.6)$ & 20 & $X^{2}=61.0$ \\
\hline & No 104(95.4) & $25(62.5)$ & 129 & $\mathrm{df}=1, \mathrm{p}=0.001$ \\
\hline & 119 & 30 & $149(100)$ & \\
\hline
\end{tabular}

Table 3. Participants' rate of monitoring blood pressure and preventive practices on hypertension Lagos, Nigeria, May 2017.

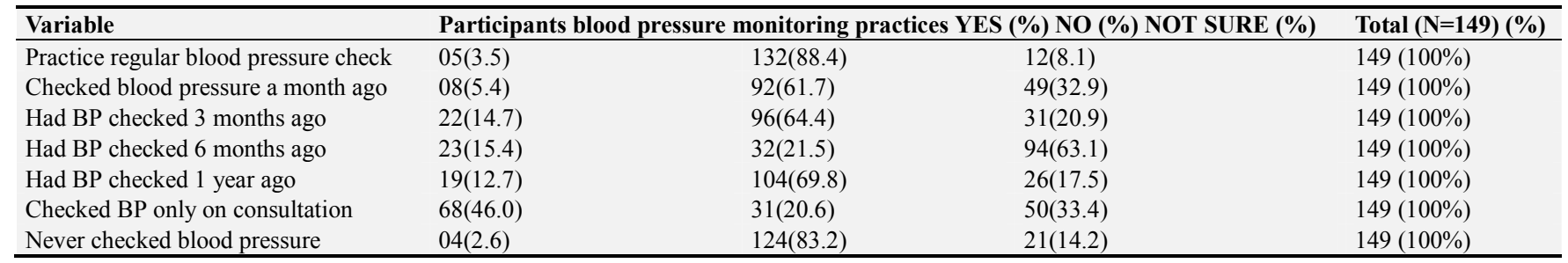

Note. Good practices $=$ when an adult carried out blood pressure check regularly from one to three times monthly. Poor practices $=$ when an adults carried out blood pressure check within 6 months to 1 year, or only on consultation and never checked.

\subsection{Blood Pressure Monitoring Practices}

Table 3 shows the rate of blood pressure monitoring among the participants and it was discovered to be low as the study indicated that $n=05,3.5 \%$ of the participants practices regular blood pressure check while nearly half of the participants $n=68(46.0 \%)$ reported they checked their blood pressure only on consultation at health institutions, and $n=04$
(2.6\%) of the participants indicated that they had never checked their blood pressure.

\section{Discussion}

The result of this study shows that there is significant association between preventive practices on hypertension and predictors like: age, marital status, sex, education level, 
knowledge of the risk factor, and complications of hypertension at $p<0.05$. Contrarily, the occupation status of the participants was not a predictor of preventive practices on hypertension, as it was not significant in this study. The association of age may be due to the fact that older adults pay attention to their health compared to young adults [15]. The married participants found to observe preventive practices on hypertension could probably be due to the support of their spouses who assisted them to achieve good health status [1617]. The education level was also found to be a predictor of preventive practices on hypertension because the association was significant, although the probable reasons were not identified in this study. The findings of this study agreed with that of a study which found high rate of preventive practices on hypertension among individuals with high level of education compared with less educated people [18]. The variables, such as knowledge of risk factors of hypertension, knowledge that hypertension has no symptom and could only be controlled, were all predictors of compliance with practices of blood pressure check, as the finding was significantly at $\mathrm{p}<0.05$. The knowledge of stroke as a complication of hypertension was not a predictor of practice of blood pressure monitoring in this study as the Chi-square was not significant. This study revealed that $89 \%$ of the participants do not observed preventive practices on hypertension based on the symptomless nature of the disease [2]. Sixty-three percent of the participants were not aware that using certain drugs could be a contributory factor towards developing hypertension. [7]. The finding on use of drug is consistent with the finding of a study conducted in Nigeria which reported that $64 \%$ of the participants were not aware that preventive practice on hypertension could be related to consumption of drugs. It is known that steroid drugs, nicotine, caffeine and food with excess salt could contribute to development of hypertension [8-9]. Thirty-four percent of the participants reported they were exposed to sedentary lifestyle due to nature of their work and this is one of the risk factors that could lead to hypertension, while $41 \%$ were eating diet rich in salt. Majority of the participants were smokers cigarette and were overweight and these habit could constitute risk factors in hypertension [10-11]. The findings on preventive practice with regard to blood pressure monitoring shows that $4 \%$ of the participants practice regular blood pressure check, while nearly half of the participants $46 \%$ reported that they checked their blood pressure only on consultation at health institutions. The implication of this is that the practice of blood pressure check is very low and there is need for improvement because that is the simplest way of screening an adult for hypertension. The limitation of this study is that the findings were applicable primarily to adults in Ikoyi, Nigeria and could not be generalized. Also, the findings were based on the analysis of the participants' responses on the questionnaires and this could be prone to recall bias. It is recommended that public health strategies like health promotion program should be designed to focus on preventive practices on hypertension in Ikoyi, Nigeria. The government, NGOs and other stakeholders in health sector could improve the level of preventive practices on hypertension among adults especially on the symptomless nature of the disease by encouraging a positive lifestyle modification, through information, education and communication (IEC) [19-20]. Future research could determine what could facilitate positive behavioral change among adults by employing a theoretical framework that will incorporate cultural, ethnic, religious and socio-economic diversity in the community [21]. It is recommended that adults could have their own electronic sphygmomanometer for easy accessibility, and regular monitoring of their blood pressure at home.

\section{Conclusions}

Knowledge of the risk factors in hypertension and its complications were found to be predictors of preventive practices on hypertension. Similarly, age, sex, marital status, and education attainment were predictors of preventive practices on hypertension, but occupational status was not significant in this study. Adults are encouraged to engage in preventive practices on hypertension to reduce risk of disability and mortality associated with hypertension in our community. It is recommended that adults should not wait to attain certain age bracket or education level before active engagement in preventive practices on hypertension, considering the peril and complications of the disease.

\section{Authors Contribution}

TOR: Design, conceptualized, collected and analyzed data, and prepared the manuscript.

AD: Proof read the manuscript.

\section{Conflict of Interest}

The authors do not have any possible conflicts of interest.

\section{References}

[1] Adamu UG, Ibok IO, Abdullahi A, Ogundele IO, Okuku GA. Knowledge, attitude and practice of physicians in the treatment of hypertension in North-central Nigeria. World $\mathrm{J}$ of Cardiovascular Diseases. 2014; 04(5): 45928-5.

[2] Dan W, Oyunbileg G, Janchiv O. Hypertension and hypertension-related disease in Mongolia; Findings of a national knowledge, attitudes and practices study. BMC Public Health, 2013; 13. 194. ISSN 1471-2458.

[3] Piper MA, Evans CV, Burda BU, Margolis KL, O'Connor E, Whitlock EP. Diagnostic and predictive accuracy of blood pressure screening methods with consideration of rescreening intervals: a systematic review for the U.S. Preventive Services Task Force. Ann Intern Med. 2015; 162(3): 192-204.

[4] Howes F, Hansen E, Nelson M. Management of hypertension in general practice. A qualitative needs assessment of Australian GPs. 2012; (41)5: 317-323. 
[5] IkeSO, Aniebue PN, Aniebue UU. Knowledge, perception and practice of lifestyle-modification measures among adult hypertensive's in Nigeria. Trans Royal Society of tropical Medical hygiene. 2010; 104: 55-60.

[6] Slark J, Khan MS, Bentley P, SharmaP. Knowledge of blood pressure in a UK general public population. Jof Human Hypertension. 2014; 28(8), 500-503. doi:10.1038/jhh.2013.136.

[7] Tenth Report of the Joint National Committee on Prevention, Detection, Evaluation, and Treatment of High Blood Pressure (The JNC $8^{\text {th }}$ Report). JAMA 2013; 289:2560-2572.

[8] James PA, Oparil S, Carter BL, et al. Evidence-based guideline for the management of high blood pressure in adults: report from the panel members appointed to the Eighth Joint National Committee (JNC 8). JAMA. 2014; 311(5):507-520. PubMed Article.

[9] Ajayi IO, Sowemimo IO, AkpaOM, Ossai NE. Prevalence of hypertension and associated factors among resident of IbadanNorth Local Government Area of Nigeria. Nig. J Cardiol. 2016; 13: 67-75.

[10] Okpechi IG, Chukwuonye II, Tiffin N, Madukwe OO, Onyeonoro UU, et al. Blood pressure gradients and cardiovascular risk factors in urban and rural populations in Abia State South Eastern Nigeria using WHO STEPwise approach. 2013; PLoS ONE: e7303.

[11] Osuala EO, Abimbola OO, Kadiri S. Knowledge, attitude to hypertension and lifestyle habits of rural dwellers in OwerreNkwoji, Imo State Nigeria. $J$ of Public Health and Epidemiology. 2014; 6: 48-51.

[12] Demaio AR, Otgontuya D, de Courten M, Bygbjerg IC, Enkhtuya $\mathrm{P}$, et al. Hypertension and hypertension-related disease in mongolia; findings of a national knowledge, attitudes and practices study. BMC Public Health. 2015; 13: 194.
[13] Oladapo OO, Salako L, Sadiq L, Soyinka K, Falase AO. Knowledge of hypertension and other risk factors for heart disease among Yoruba rural South Western Nigeria. BJMMR. 2013; 4: 993-1003

[14] Bandura A. Social Learning Theory. New York: 1977; General Learning PressBalogun MO, Olugbenga O. Prevalence of hypertension in three rural communities of Ife north local Government Area of Osun state, south West Nigeria. International Journal of General Medicine. 2013; 6: 863-868.

[15] Balogun MO, Olugbenga O. Prevalence of hypertension in three rural communities of Ife north local Government Area of Osun state, south West Nigeria. International Journal of General Medicine. 2013; 6: 863-868.

[16] Ige OK, Owoaje ET, Adebiyi OA.Non communicable disease and risky behavior in an urban University Community in Nigeria. Afr Hlth Sci. 2013; 13:62-67.

[17] Egan BM, Zhao Y, Axon RN. US trends in prevalence, awareness, treatment, and control of hypertension1988-2008. JAMA. 2010; 303: 2043-2050.

[18] Iyalomhe GB, Iyalomhe SI. Hypertension-related knowledge, attitudes and life-style practices among hypertensive patients in a sub-urban Nigerian community. Journal of Public Health and Epidemiology. 2010; 2:71-77.

[19] Ekwunife OI, Udeogaranya PO, Nwatu IL. Prevalence, awareness, treatment and control of hypertension in a Nigerian population. Health. 2010; 2: 731-735.

[20] U. S. Preventive Services Task Force. Screening for high blood pressure in adults: U. S. Preventive Services Task Force recommendation statement. Ann Intern Med. 2015; 163(10): 778-786.

[21] Eugene V, Bourne PA. Hypertensive patients: knowledge, selfcare management practices and challenges. $\mathrm{J}$ of Behavral Health. 2013; 2(3): 259-268. 